\title{
DYNAMICS OF EXTINCTION IN COUPLED POPULATIONS OF THE FLOUR BEETLE Tribolium castaneum
}

\author{
GODOY, W. A. C. ${ }^{1}$ and COSTA, M. I. S. ${ }^{2}$ \\ ${ }^{1}$ Departamento de Parasitologia, IB, Universidade Estadual Paulista, CEP 18618-000, Botucatu, SP, Brazil and \\ Centro Virtual de Pesquisa Ciência e Computação para a Complexidade, UNESP \\ ${ }^{2}$ Coordenação de Sistemas e Controle, Laboratório Nacional de Computação Científica, MCT, Av. Getúlio Vargas, 333 \\ Quitandinha, CEP 25651-070, Petrópolis, RJ, Brazil \\ Correspondence to: Wesley A. C. Godoy, Departamento de Parasitologia, IB, Universidade Estadual Paulista, \\ CEP 18618-000, Botucatu, SP, Brazil and Centro Virtual de Pesquisa Ciência e Computação para a \\ Complexidade, UNESP, e-mail: wgodoy@ibb.unesp.br \\ Received August 29 - Accepted October 22 - Distributed May 31, 2005
}

(With 5 figures)

\begin{abstract}
In this study we analyzed the effect of migration on the persistence time of coupled local populations of Tribolium in different environments. Four treatments were set up to compare different levels of environmental heterogeneity. We established high, low, moderate, and no heterogeneity. These levels were estimated by the different amounts of food offered to each population. To investigate how risk spreading works, a stochastic model for two subpopulations was employed. The high heterogeneity treatment resulted in the longest persistence, even though survival analysis revealed no significant difference among treatments. The magnitude of differences in growth rates among subpopulations is probably associated with persistence.
\end{abstract}

Key words: coupled populations, Tribolium, environmental heterogeneity, population dynamics, model.

\section{RESUMO}

\section{Dynamics of extinction in coupled populations of the flour beetle Tribolium castaneum}

Neste estudo analisamos o efeito da migração sobre o tempo de persistência de populações acopladas de Tribolium em diferentes ambientes. Quatro tratamentos foram estabelecidos para comparar diferentes níveis de heterogeneidade ambiental, alto, moderado, baixo e nulo. Os níveis de heterogeneidade foram estabelecidos por meio de diferentes quantidades de alimento oferecidas a cada população. Para investigar como funciona a expansão de risco entre populações conectadas, um modelo estocástico para duas populações acopladas foi empregado. O tratamento estabelecido para analisar a alta heterogeneidade ambiental foi o que exibiu maior tempo de persistência, apesar da análise de sobrevivência não revelar diferença significativa entre os tratamentos. A magnitude da diferença nas taxas de crescimento entre as populações provavelmente está associada ao tempo de persistência populacional.

Palavras-chave: populações acopladas, Tribolium, heterogeneidade ambiental, dinâmica populacional, modelo.

\section{INTRODUCTION}

The forces that affect population size, age structure, and genetic composition include birth and death rates, behavioral interactions among individuals, environmental fluctuations, natural selection, and interactions with other species (Case, 2000). Understanding temporal fluctuations in population abundance is essential in analyzing population dynamics. However, individuals comprising a population are also distributed in space (Goodwin \& Fahrig, 1998; Turchin, 1998). An approach considering both time and space is useful in detecting two potentially important factors in population dynamics: spatial population structure, 
with individuals interacting more frequently with neighbors than with more distant individuals; and environmental heterogeneity, with individuals at different locations experiencing different environments, and thus presenting different birth and death rates (Kendall \& Fox, 1998; Kot, 2001).

The study of spatially structured populations in environments that are not constant over time is currently of prime interest (Gilpin \& Hanski, 1991; Pimm, 1991; Rosenzweig, 1995). Spatial structure is frequently invoked to explain competitive coexistence (Iwasa \& Roughgarden, 1986; Nee \& May, 1992), the persistence of predator-prey and hostparasitoid interactions (Reeve, 1988; Sabelis \& Diekmann, 1988; Comins et al., 1992), and the regional persistence of small populations subject to local stochastic extinction (den Boer, 1981; Day \& Possingham, 1995). Spatial structure is also the key feature of metapopulation models (Gilpin \& Hanski, 1991; Hanski \& Gilpin, 1997).

The spatial component of population dynamics has inspired a variety of modeling formalisms, which differ in grain and detail (Hanski, 1994). Several types of models have been used to explore the role of spatial heterogeneity in population, metapopulation, and community dynamics (Taylor, 1988; Kareiva, 1990; Hanski, 1991, 1994). Most metapopulation models are based on measures of presence or absence in habitat patches interconnected by migration (Hanski, 1991, 1994). They are stochastic because colonization and extinction of patches are random events contingent on patch area and relative spatial isolation (Roughgarden, 1998; Renshaw, 1999).

Environmental heterogeneity has most frequently been studied within the context of sourcesink dynamics (Pulliam, 1988; Pulliam, 1996; Frouz \& Kindlmann, 2001). A source is a subpopulation in which births exceed deaths and emigration exceeds immigration, and which thus may be considered a net exporter of individuals (Pulliam, 1988). A sink, on the other hand, is a subpopulation in which deaths exceed births and immigration exceeds emigration (Pulliam, 1988).

Since in the real world some habitats are clearly more suitable for survival and/or reproduction than others (Pulliam, 1996), individuals migrating between habitats of different quality are subject to change of life conditions, which can affect their growth rates (Roughgarden, 1998). Therefore, migration is an important factor in preventing extinction in sink populations (Pulliam, 1996; Frouz \& Kindlmann, 2001).

The effect of random environmental variation on population dynamics has also been well documented (Pimm, 1991; Ariño \& Pimm, 1995). A population in a variable environment with exchange of individuals between subpopulations will experience variation in both time and space. At any given moment, each subpopulation may not be perfectly correlated with other subpopulations (Ranta et al., 1995). Hence, both the degree of correlation with environmental variation and the dispersal pattern among subpopulations could affect both local and global dynamics.

One approach in examining the complexity of these relationships is to experimentally investigate populations under carefully controlled conditions. Flour beetles of the genus Tribolium have been used in this fashion for over sixty years (Chapman, 1928; Park et al., 1964; Young, 1970; Jillson, 1980; Costantino \& Desharnais, 1981; Hastings \& Costantino, 1987; Dennis et al., 1995; Costantino et al., 1995, 1997, 1998). Laboratory populations are easily cultured and many species can complete their life cycle in less than a month (Dennis et al., 1995). Population attributes such as density and age structure are readily measured and the populations themselves can be replicated (Dennis et al., 1995). For this reason, the flour beetle has been used in many ecological investigations, where aspects such as the regulation of density and species competition have been studied (Henson \& Cushing, 1997; Costantino et al., 1998). Some species of Tribolium are cannibalistic (Park et al., 1965). Adults feed on eggs, larvae, pupae, and callows while larvae eat eggs, pupae, and callows. Neither larvae nor adults eat mature adults and larvae do not feed on larvae (Dennis et al., 1995). This level of complexity renders the Tribolium system an excellent experimental model for theoretical and empirical studies.

In the present study we analyzed both experimentally and theoretically the effect of migration on persistence time and population growth of experimental coupled populations of Tribolium castaneum in two different environments. Our study is an attempt to evaluate the behavioral patterns of populations as well as their dynamics of extinction through interactions between environmental heterogeneity and interpatch migration. We believe that the Tribolium system can illustrate very well how the source populations may rescue sink populations in a 
population structure with two dimensions: migration and environmental heterogeneity.

\section{MATERIAL AND METHODS}

\section{Tribolium experiments}

Experiments were set up at the Department of Environmental Science and Policy, University of California, Davis, U.S.A. Beetle populations were grown in small bottles with 5, 10, 15, 20, 30, and 35 grams of standard medium (95\% flour, 5\% brewer's yeast). All populations were housed in the same environmental chamber at $31^{\circ} \mathrm{C}$. Populations were paired. Different amounts of food were offered to each pair. Four treatments were set up to compare different levels of environmental heterogeneity: high (vials with 5 and $35 \mathrm{~g}$ ), moderate (10 and $30 \mathrm{~g}$ ), low (15 and $25 \mathrm{~g}$ ), and no heterogeneity (20 and $20 \mathrm{~g}$ ). A corridor effect was achieved by exchanging $10 \%$ of the adult population between pairs of each generation. Initial populations in each pair of bottles totaled $50\left(\mathrm{~N}^{1}+\mathrm{N}^{2}=50\right)$. Of these 50 , one bottle received the dispersing fraction and the other received the non-dispersing fraction. The initial sizes of paired populations were always 5 for vials with $5,10,15$, and 20 grams, and 45 for vials with $35,30,25$, and 20 grams. There were twelve replicate pairs per treatment.

The experimental protocol produced discrete generations at seven-week intervals. Adults were introduced to the medium for one week to oviposit and then removed, thus simulating adult mortality and destabilizing these populations (Costantino et al., 1997). Seven weeks later, adults from the subsequent generation were counted. These output numbers were used to determine the initial size of the next generation, according to the following formula:

$$
\begin{aligned}
& \mathrm{N}^{1}{ }_{\mathrm{d}}=(1-\mathrm{d}) \mathrm{N}_{\mathrm{t}+1}^{1}+\mathrm{dN}^{2}{ }_{\mathrm{t}+1} \\
& \mathrm{~N}_{\mathrm{d}}^{2}=\mathrm{dN}^{1}{ }_{\mathrm{t}+1}+(1-\mathrm{d}) \mathrm{N}^{2}{ }_{\mathrm{t}+1}
\end{aligned}
$$

where $d$ is the exchange rate, and $N_{d}$ refers to the population size after dispersal. $\mathrm{N}_{\mathrm{d}}$ is then used as $\mathrm{N}_{\mathrm{t}}$ to begin the next generation. Six generations were investigated for a total period of 35 weeks.

\section{Statistical analysis}

Survival analysis was run using Kaplan-Meier survival curves and the log-rank test to compare survival curves from each treatment. The general equation for a Kaplan-Meier survival probability at failure time $t_{(j)}$ can be written as

$$
\hat{S}\left(t_{(j)}\right)=\hat{S}\left(t_{(j-1)}\right) \times \operatorname{Pr}\left(\hat{T}>t_{(j)} \mid T>t_{(j)}\right)
$$

This equation gives the probability of surviving past the previous failure time $t_{(j-1)}$, multiplied by the conditional probability of surviving past time $t_{(j)}$, given survival to at least time $t_{(j)}$. We performed this analysis using SAS software (SAS, 1991).

\section{Model}

The model for two subpopulations can be written as

$$
\begin{gathered}
\mathrm{N}_{1, \mathrm{t}+1}=\mathrm{r}_{1, \mathrm{t}}\left((1-\mathrm{m}) \mathrm{N}_{1, \mathrm{t}}+\mathrm{mN}_{2, \mathrm{t}}\right) \\
\mathrm{N}_{2, \mathrm{t}+1}=\mathrm{r}_{2, \mathrm{t}}\left(\mathrm{mN}_{1, \mathrm{t}}+(1-\mathrm{m}) \mathrm{N}_{2, \mathrm{t}}\right)
\end{gathered}
$$

In this model, $m$ is the probability that an organism from subpopulation-1 disperses to subpopulation-2, and vice versa. In short, it is the probability that an organism will migrate (Roughgarden, 1998). Therefore, $(1-\mathrm{m})$ is the probability that an organism will stay in its origin patch and will not migrate to another. $N_{x, t}$ is the number of individuals at time $t$ in the subpopulation at location $x$, where $x$ is 1 or 2 . The geometric growth rate at location $x$ at time $t$ is $r$. If $m$ is zero, the equations describe two separate uncoupled populations. On the other hand, if $m$ is $1 / 2$ the two populations are completely mixed and are in effect one population. Two growth rates $\left(r_{1}\right.$ and $\left.r_{2}\right)$ were employed in the simulations obtained from $N_{1}$ and $N_{2}$ subpopulations to simulate the effect of environmental stochasticty. Using a random number generator, the growth rates were set in each loop of the equations. When the random number was less than $1 / 2$, the lowest $r$ was used. If the random number was more than $1 / 2$, the highest $r$ was used.

\section{RESULTS}

The survival curves were very similar and the statistical analysis revealed no significant difference among treatments $\left(\chi^{2}=4.85 ; \mathrm{p}>0.18\right)$, suggesting that Tribolium populations exhibit similar persistence dynamics in spite of the migration between source and sink populations. Global extinctions were observed in all treatments, although different numbers of extinct populations were found for each environment. With high environmental heterogeneity ( 5 and $35 \mathrm{~g}$ of food), six populations 
of Tribolium became extinct within three generations (14 weeks). The pattern of population persistence is shown in Fig. 1A. All the coupled populations extinct within three generations exhibited the same growth rates: $r_{1}=0.4472$, and $r_{2}=0.1491$. The simulations run indicated global extinction by the third generation (Fig. 1B). With moderate environmental heterogeneity (10 and $30 \mathrm{~g}$ of food) eleven global extinctions were detected. Seven of them became extinct by the third generation $\left(r_{1}=\right.$ 0.4472 , and $\left.r_{2}=0.1491\right)$ and four $\left(r_{1}=0.6687\right.$, and $r_{2}=0.3861$ ) by the fifth generation (Fig. 2A). The simulations run by setting $r_{1}=0.6687$ and $r_{2}=$ 0.3861 also revealed global extinction by the fifth generation (Fig. 2B).

With low environmental heterogeneity ( 15 and $25 \mathrm{~g}$ of food) nine global extinctions were observed. Five coupled population were extinct by the third generation $\left(r_{1}=0.4472\right.$, and $\left.r_{2}=0.1491\right)$ and four by the fifth $\left(r_{1}=0.6687\right.$, and $\left.r_{2}=0.3861\right)$. As for influencing growth rates, the simulations performed in this treatment exhibited the same results as those observed in the other treatments (Fig. 3A and 3B). With no environmental heterogeneity, nine coupled populations became extinct. However, only two became extinct in three generations $\left(r_{1}=0.4472\right.$, and $\left.r_{2}=0.1491\right)$, while three $\left(r_{1}=0.5848\right.$ and $r_{2}=$ 0.2811 ) were extinct by four generations (Fig. 4A) and four by five generations $\left(r_{1}=0.6687\right.$ and $r_{2}=$ $0.3861)$. The simulations also showed the same results found in other treatments, including global extinction by four generations (Fig. 4B). The treatment in which environmental heterogeneity was highest exhibited the longest time of global persistence (Fig. 5A). Simulating the coupled dynamics with $r_{1}=1.7232$ and $r_{2}=0.4670$ results in persistence for an indeterminate period of time (Fig. 5B).

A

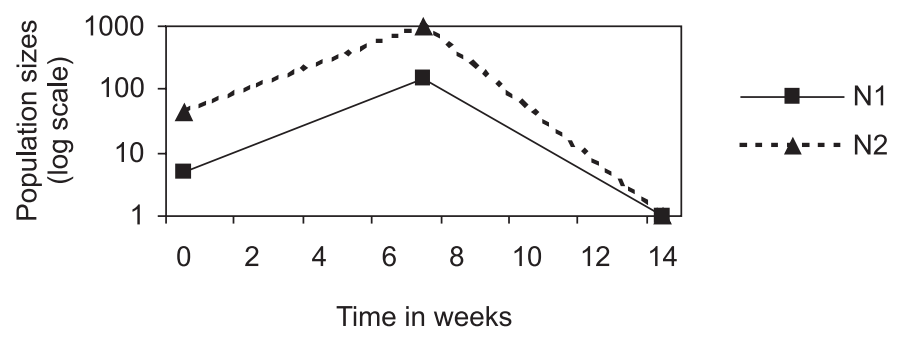

B

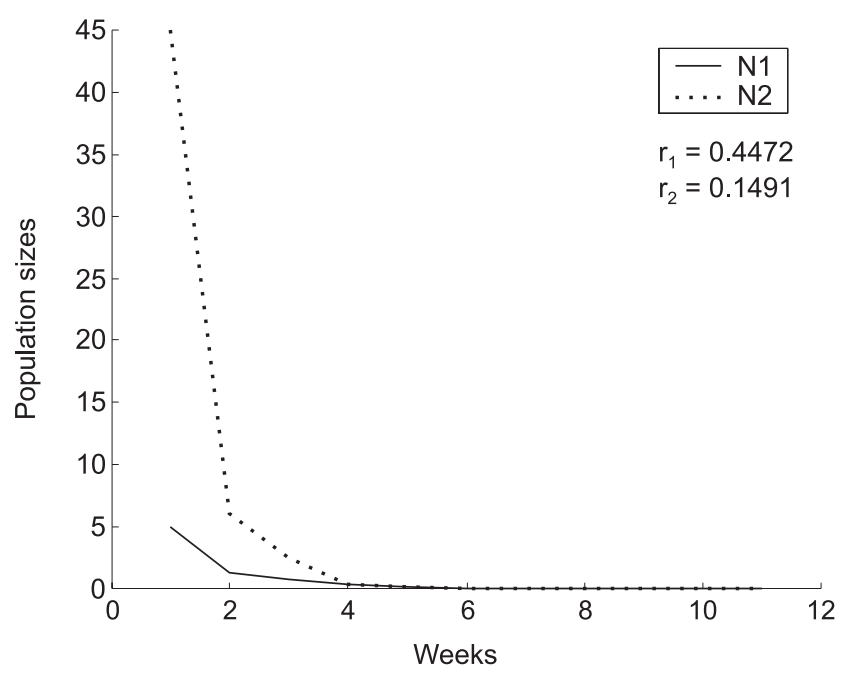

Fig. 1 - Persistence in experimental coupled populations of Tribolium castaneum (A) with high environmental heterogeneity and simulations run with a stochastic coupled population model (B). 
A

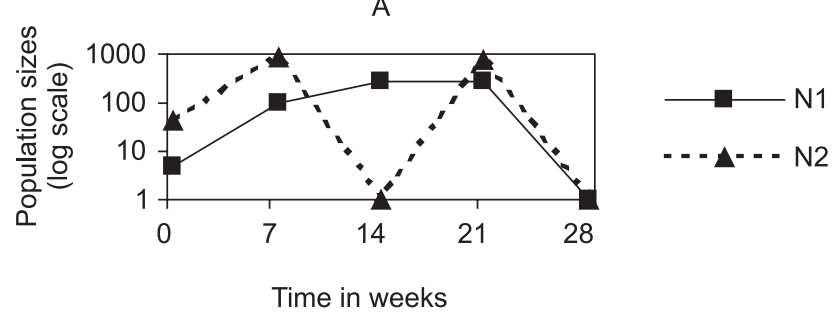

B

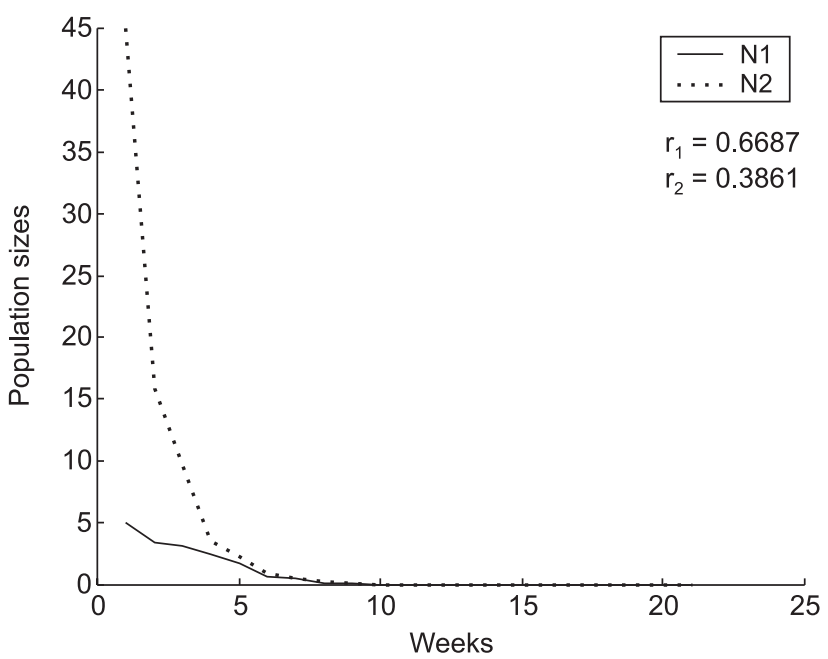

Fig. 2 - Persistence in experimental coupled populations of Tribolium castaneum (A) with moderate environmental heterogeneity and simulations run with a stochastic coupled population model (B).

\section{DISCUSSION}

A very interesting finding of the present study was that survival curves were not significantly different. The similarity among them in spite of different treatments may indicate the presence of compensatory mechanisms by Tribolium populations. Tribolium species could utilize cannibalism as a compensatory mechanism when the carrying capacity is not enough to maintain population persistence. Cannibalism may change competitive interactions, on one hand, by eliminating competitors and, on the other, by compensating for food scarcity through the nutritional benefits acquired (Fox, 1974; Johansson, 1992; Fincke, 1994).

Evidence that cannibalism is nutritionally beneficial comes from direct observations (Fox, 1974; Agarwala \& Dixon, 1992; Tschinkel, 1993). Other observations have verified that cannibalism increases when the natural food source is scarce
(Fox, 1974; Polis, 1981; Naseer \& Abdurahiman, 1993). Some authors have also suggested that cannibalism may allow persistence of populations during food scarcity periods (Agarwala \& Dixon, 1992; Naseer \& Abdurahiman, 1993; Parajulee \& Phillips, 1995). There is evidence that cannibalism can facilitate colonization of new environments since cannibals can use intraspecific predation to compensate for resource scarcity in places to which invader species have not yet adapted (Johansson, 1996; Wissinger et al., 1996; Via, 1999).

Although we did not detect significant differences among treatments, we did determine a slight impact on persistence time due to $50 \%$ of the coupled populations from environments with high heterogeneity (vials with 5 and $35 \mathrm{~g}$ ) population persisting to the last generation studied. In a classic study, Jillson (1980) investigated the responses of $T$. castaneum populations cultured in a series of regularly fluctuating environments and observed that the total population numbers in a 
periodically fluctuating environment were more than twice those found in a constant environment, even though the average flour beetle volume was the same in both cases. In our experiments there were no fluctuating environments; however, the individuals were moved from a source environment to a sink environment. Local environmental variability usually interferes with population dynamics, influencing birth rate and extinction dynamics (Moran, 1953; Palmqvist \& Lundberg, 1998; Ranta et al., 1995).

The present results also suggest that coupled populations with very different growth rates $\left(r_{l}\right.$ and $r_{2}$ ) are more susceptible to stochastic variation, which may contribute to the persistence of populations over a long period of time. Demographic and environmental stochasticity can strongly affect both local population dynamics and synchrony between them, leading to the deterministic extinction found locally or globally, which may occur due to scramble competition in large cohorts. Several studies using stochastic models have explored this possibility and shown that carrying capacity and demographic and environmental stochasticity play an essential role in population persistence (Soulé, 1987; Burgman et al., 1988; Wissel \& Stöcker, 1991; Gabriel \& Bürger, 1992). Theoretical studies have shown that population persistence in patchy environments results from an interaction between local densitydependence, dispersal, and spatial heterogeneity (Chesson, 1981; Kareiva, 1990). Negative densitydependence may cause populations to increase when rare, but positive density-dependence may cause populations to go extinct when rare (Amarasekare, 1998).

A

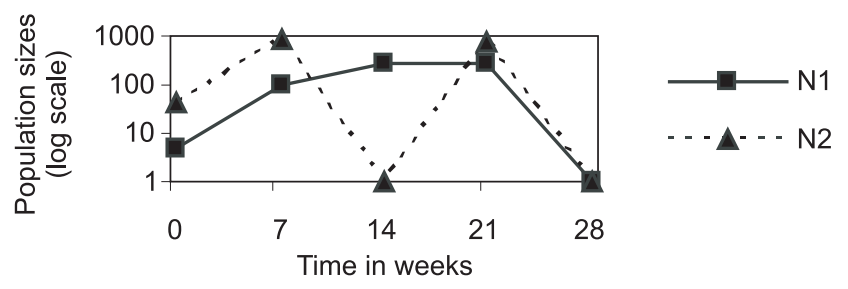

B

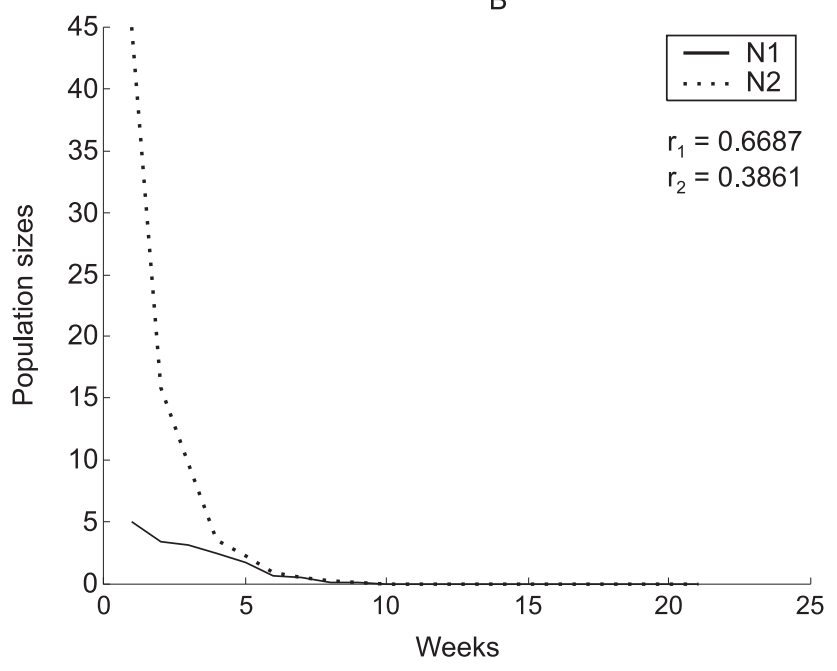

Fig. 3 - Persistence in experimental coupled populations of Tribolium castaneum (A) with low environmental heterogeneity and simulations run with a stochastic coupled population model (B). 
A

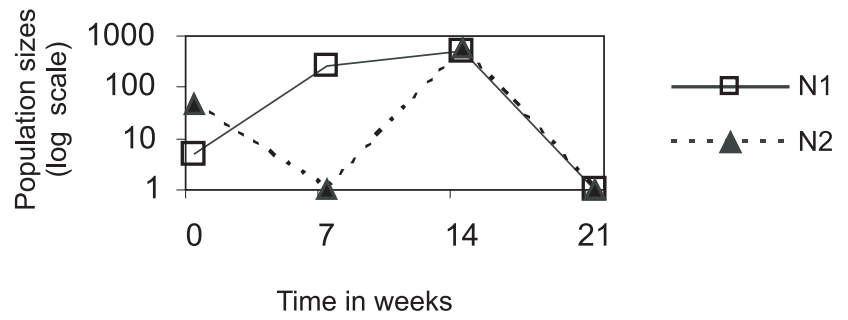

B

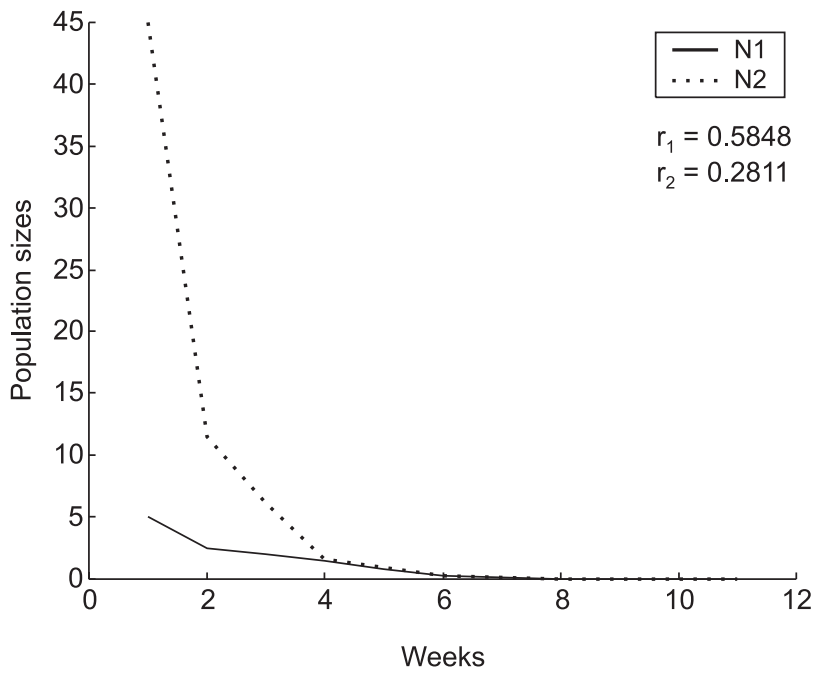

Fig. 4 - Persistence in experimental coupled populations of Tribolium castaneum (A) with no environmental heterogeneity and simulations run with a stochastic coupled population model (B).

The main feature of this study was combining migration with environmental heterogeneity, and one of the most interesting results found suggests that stochasticity occurs with more significance in coupled environments with high heterogeneity levels. Theoretical and empirical studies have revealed that fluctuation in coupled populations may emerge as a consequence of spatially uncorrelated stochasticity in both extinction and colonization events (Hanski, 1994). Actually, environmental stochasticity affecting extinction rates is often more or less spatially correlated. The prime example is year-to-year variation in weather conditions, which greatly impact most insect populations (Andrewartha \& Birch, 1954).

Spatially correlated environmental stochasticity, or regional stochasticity as it is sometimes called
(Hanski, 1991), is expected to reduce metapopulation size and longevity (Gilpin, 1990; Harrison \& Quinn, 1990; Hanski, 1991). The absence of environmental correlation inherent in environments with high heterogeneity, such as those designed in the present study, probably promotes a significant difference between growth rates in each patch, which characterizes the system as a source-sink, while at the same time causing unpredictable results relative to population growth.

We believe that the balance between temporal and spatial environmental variability can determine the level of local population variability and synchrony, with implications for the dynamics of both local and global extinction. Hence, the global extinction risk can be directly determined by features of local population dynamics. 
A

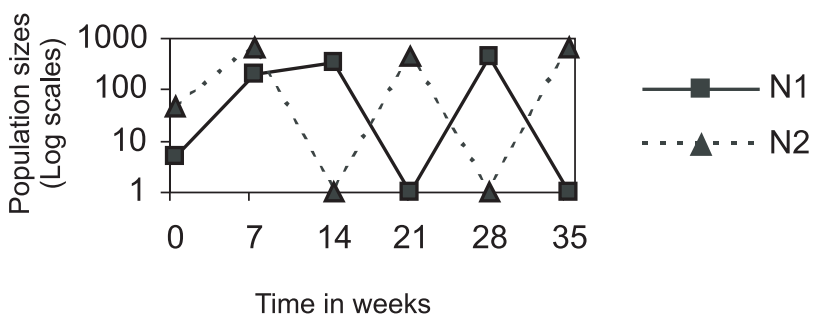

B

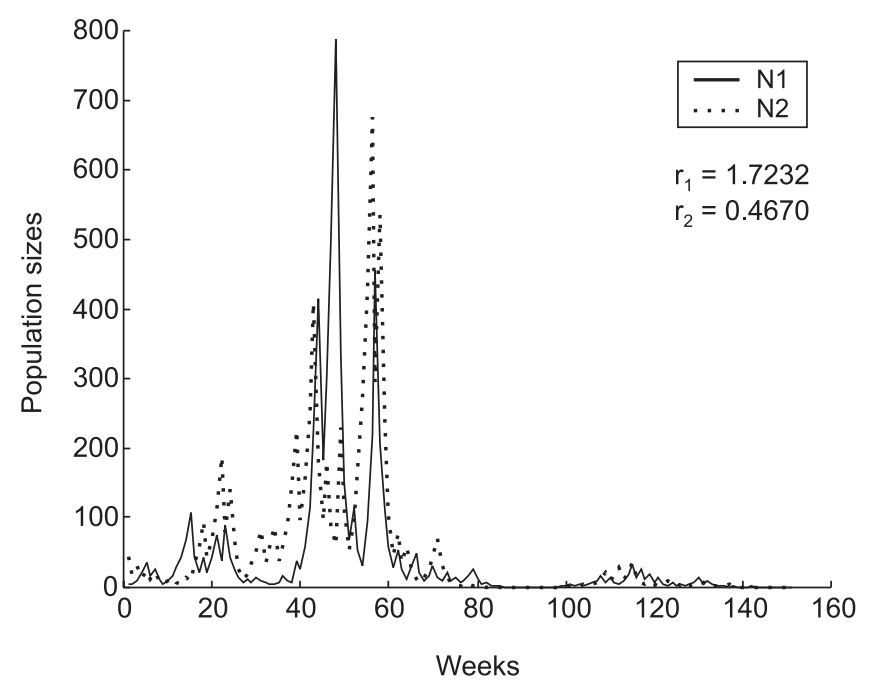

Fig. 5 - Persistence in experimental coupled populations of Tribolium castaneum (A) with the highest environmental heterogeneity and simulations run with a stochastic coupled population model (B).

Acknowledgements - This study was supported by FAPESP (98/ 7474-6).

\section{REFERENCES}

AGARWALA, B. K. \& DIXON, A. F. G., 1992, Laboratory study of cannibalism and interspecific predation in ladybirds. Ecol. Entomol., 17: 303-309.

AMARASEKARE, P., 1998, Allee effects in metapopulation dynamics. Am. Natur., 152: 298-302.

ANDREWARTHA, H. G. \& BIRCH, L. C., 1954, The distribution and abundance of animals. The University of Chicago Press, $782 \mathrm{p}$.

ARIÑO, A. \& PIMM, S. L., 1995, On the nature of population extremes. Evol. Ecol., 9: 429-443.

BURGMAN, M. A., AKCAKAYA, H. R. \& LOEW, S. S., 1988, The use of extinction models for species conservation. Biol. Conserv., 43: 9-25.
CASE, T. J., 2000, An illustrated guide to theoretical ecology. Oxford University Press, 449p.

CHAPMAN, R. N., 1928, Quantitative analysis of environmental factors. Ecology, 9: 111-122.

CHESSON, P. L., 1981, Models for spatially distributed populations: the effect of within-patch variability. Theor. Popul. Biol., 19: 288-325.

COMINS, H. N., HASSELL, M. P. \& MAY, R. M., 1992, The spatial dynamics of host-parasitoid systems. J. Anim. Ecol., 61: 735-748

COSTANTINO, R. F. \& DESHARNAIS, R. A., 1981, Gamma distributions of adult numbers for Tribolium populations in the region of their steady states. J. Anim. Ecol., 50: 667-681.

COSTANTINO, R. F., CUSHING, J. M., DENNIS, B. \& DESHARNAIS, R. A., 1995, Experimentally induced transitions in the dynamic behaviour of insect populations. Nature, 375: 227-230. 
COSTANTINO, R. F., DESHARNAIS, R. A., CUSHING, J. M. \& DENNIS, B., 1997, Chaotic dynamics in an insect population. Science, 275: 389-391.

COSTANTINO, R. F., CUSHING, J. M., DENNIS, B., DESHARNAIS, R. A. \& HENSON, S. M., 1998, Resonant population cycles in temporally fluctuating habitats. Bull. Mat. Biol., 60: 247-273.

DAY, J. R. \& POSSINGHAM, H. P., 1995, A stochastic metapopulation model with variability in a patch size and position., Theor. Popul. Biol., 48: 333-360.

DEN BOER, P. J., 1981, On the survival of populations in a heterogeneous and variable environment. Oecologia, 50: 3953.

DENNIS, B. R., DESHARNAIS, A., CUSHING, J. M. \& COSTANTINO, R. F., 1995, Nonlinear demographic dynamics: mathematical models, statistical methods and biological experiments. Ecol. Monog., 65: 261-281.

FINCKE, O. M., 1994, Population regulation of a tropical damselfly in the larval stage by food limitation, cannibalism, intraguild predation and habitat drying. Oecologia, 100: 118-127.

FOX, L. R., 1974, Cannibalism in natural populations. Ann. Rev. Ecol. Syst., 6: 87-106.

FROUZ, J. \& KINDLMANN, P., 2001, The role of sink to source re-colonisation in the population dynamics of insects living in unstable habitats: an example of terrestrial chironomids. Oikos, 93: 50-58.

GABRIEL, W. \& BÜRGER, R., 1992, Survival of small populations under demographic stochasticity. Theor. Popul. Biol., 41: 44-71.

GILPIN, M. E., 1990, Extinction of finite metapopulations in correlated environments. In: B. Shorrocks \& I. R. Swingland (eds.), Living in a Patchy Environment. Oxford Science Publications, pp. 177-186.

GILPIN, M. \& HANSKI, I., 1991, Metapopulation dynamics: empirical and theoretical investigations. Academic Press, London, 313p.

GOODWIN, B. J. \& FAHRIG, L., 1998, Spatial scaling and animal population dynamics. In: D. L. Peterson \& V. T. Parker (eds.), Ecological scale, theory and applications. Columbia Univ. Press, NY.

HANSKI, I., 1991, Single-species metapopulation dynamics: concepts, models and observations. Biol. J. Linn. Soc., 42: 17-38.

HANSKI, I., 1994, A practical model of metapopulation dynamics. J. Anim. Ecol., 63: 151-162.

HANSKI, I. \& GILPIN, M., 1997, Metapopulation biology: ecology, genetics and evolution. Academic Press, 512p.

HARRISON, S. \& QUINN, J. F., 1990, Correlated environments and the persistence of metapopulations, Oikos, 56: 293-298.

HASTINGS, A. \& COSTANTINO, R. F., 1987, Cannibalistic egglarva interactions in Tribolium: an explanation for the oscillations in population numbers. Am. Natur., 120: 36-52.

HENSON, S. M. \& CUSHING, J. M., 1997, The effect of periodic habitat fluctuations on a nonlinear insect population model. J. Math. Biol., 36: 201-226.
IWASA, Y. \& ROUGHGARDEN, J., 1986, Interspecific competition among metapopulations with space-limited subpopulations, Theor. Pop. Biol., 30: 194-214.

JILLSON, D. A., 1980, Insect populations respond to fluctuating environments, Nature, 288: 699-700.

JOHANSSON, G., 1992, Effects of zooplankton availability and foraging mode on cannibalism in three dragonfly larvae. Oecologia, 91: 179-183.

JOHANSSON, G., 1996, The influence of cannibalism and prey density on growth in the damselfly Coenagrion hastulatum. Arch. Für Hydrobiol., 137: 523-535.

KAREIVA, P., 1990, Population dynamics in spatially complex environments: theory and data. Phil. Trans. Roy. Soc. Lond., B330: 175-190.

KENDALL, B. E. \& FOX, G. A., 1998, Spatial structure, environmental heterogeneity, and population dynamics: analysis of the coupled logistic map. Theor. Popul. Biol., 54: 11-37.

KOT, M., 2001, Elements of mathematical ecology. Cambridge University Press, Cambridge, 464p.

MORAN, P. A. P., 1953, The statistical analysis of the Canadian lynx cycle. II. Synchronization and meteorology. Aust. J. Zool., 1: 291-298.

NASEER, M. \& ABDURAHIMAN, U. C., 1993, Cannibalism in Cardiastethus exiguus Poppius (Hemiptera: Anthocoridae): a predator of the coconut caterpillar Opsina arenolella Walker (Lepidoptera: Xylorictidae). J. Adv. Zool., 14: 1-6.

NEE, S. \& MAY, R. M., 1992, Dynamics of metapopulations: habitat destruction and competitive coexistence. J. Anim. Ecol., 61: $37-40$.

PALMQVIST, E. \& LUNDBERG, P., 1998, Population extinctions in correlated environments. Oikos, 83: 359-367.

PARAJULEE, M. N. \& PHILLIPS, T. W., 1995, Survivorship and cannibalism in Lyctocoris campestris (Hemiptera: Anthocoridae): effects of density, prey availability and temperature. J. Entomol. Sci., 30: 1-8.

PARK, T., LESLIE, P. H. \& MERTZ, D. B., 1964, Genetic strains and competition in populations of Tribolium. Physiol. Zool., 37: 97-162.

PARK, T., MERTZ, D. B., GRODZINSKI, W. \& PRUS, T., 1965, Cannibalistic predation in population of flour beetles. Physiol. Zool., 38: 289-321.

PIMM, S. L., 1991, The balance of nature? Univ. of Chicago Press.

POLIS, G. A., 1981, The evolution of dynamics of intraspecific predation. Ann. Rev. Ecol. Syst., 12: 125-251.

PULLIAM, H. R., 1988, Sources, sinks and population regulation. Am. Nat., 132: 652-661.

PULLIAM, H. R., 1996, Sources and sinks: empirical evidence and population consequences, pp. 45-69. In: O. R. Rhodes, K. Chesser \& M. Smith (eds.), Population dynamics in ecological space and time. Univ. of Chicago Press.

RANTA, E., KAITALA, V., LINDSTROM, J. \& LINDEM, H., 1995, Synchrony in population dynamics. Proc. R. Soc. Lond., B 262: 113-118. 
REEVE, J. D., 1988, Environmental variability, migration and persistence in host-parasitoid systems. Am. Nat., 132: 810836.

RENSHAW, E., 1999, Stochastic effects in population models. pp. 23-63. In: J. McGlade (ed.), Advanced ecological theory, principles and applications. Blackwell Science, pp. 23-63.

ROSENZWEIG, M. L., 1995, Species diversity in space and time. Cambridge Univ. Press, 436p.

ROUGHGARDEN, J., 1998, Primer of ecological theory. Prentice Hall, Upper Saddle River, 456p.

SABELIS, M. W. \& DIEKMANN, O., 1988, Overall population stability despite local extinction; the stabilizing influence of prey dispersal from predator-invaded patches. Theor. Pop. Biol., 34: 169-176.

SAS, 1991, SAS user's guide releaser 6.03 edition, Cary, NC.

SOULÉ, M. E., 1987, Introduction. In: M. E. Soulé (ed.), Viable populations for conservation. Cambridge University Press.

TAYLOR, A. D., 1988, Parasitoid competition and the dynamics of host-parasitoid models. Am. Natur., 132: 417-436.
TSCHINKEL, W. R., 1993, Resource allocation, brood production and cannibalism during colony founding in the fire ant, Solenopsis invicta. Behav. Ecol. Sociobiol., 33: 209-233.

TURCHIN, P., 1998, Quantitative analysis of movement: measuring and modeling population redistribution in animals and plants. Sinauer Assoc., 396p.

VIA, S., 1999, Cannibalism facilitates the use of a novel environment in the flour beetle Tribolium castaneum. Heredity, 82: $267-275$.

WISSEL, C. \& STÖCKER, S., 1991, Extinction of populations by random influences. Theor. Popul. Biol., 39: 315-328.

WISSINGER, S. A., SPARKS, G. B., ROUSE, G. L., BROWN, W. S. \& STELTZER, H., 1996, Intraguild predation and cannibalism among larvae of detritivorous caddisflies in subalpine wetlands. Ecology, 77: 2421-2430.

YOUNG, A. M., 1970, Predation and abundance in populations of flour beetles. Ecology, 51: 602-619. 